\title{
The Effects of Androstenone on the Plasma Serotonin, $\beta$-Endorphin, and Cortisol Concentrations in Thoroughbred Horses
}

\author{
Yeonju Choi and Minjung Yoon * (D)
}

check for updates

Citation: Choi, Y.; Yoon, M. The Effects of Androstenone on the Plasma Serotonin, $\beta$-Endorphin, and Cortisol Concentrations in

Thoroughbred Horses. Animals 2021, 11, 1694. https://doi.org/10.3390/ ani11061694

Academic Editor: Glenys Noble

Received: 6 May 2021

Accepted: 3 June 2021

Published: 7 June 2021

Publisher's Note: MDPI stays neutral with regard to jurisdictional claims in published maps and institutional affiliations.

Copyright: (c) 2021 by the authors. Licensee MDPI, Basel, Switzerland. This article is an open access article distributed under the terms and conditions of the Creative Commons Attribution (CC BY) license (https:/ / creativecommons.org/licenses/by/ $4.0 /)$.
Research Center for Horse Industry, Department of Animal Science and Biotechnology, Kyungpook National University, Sangju 37224, Korea; yjchoi2031@gmail.com

* Correspondence: mjyoonemail@gmail.com; Tel.: +82-84-530-1233

Simple Summary: The development of horse managing tools is needed to prevent accidents and to improve welfare for domestic horses because the safety hazards for people who are exposed to horses are well documented. Androstenone, a pheromone secreted from boars, changes the behavior of dogs to become less excited. In horses, a previous study showed that a specific receptor for androstenone was expressed in the vomeronasal organ and nasal cavity. Horses treated with androstenone also showed more compliant behaviors. Thus, this study was conducted to investigate the mechanism of androstenone for changing horse behaviors. The change in the plasma concentrations of serotonin, $\beta$-endorphin, and cortisol in response to the treatment of androstenone was evaluated using an immunoassay. The results of this study demonstrated that androstenone may control the neuroendocrine system of horses, resulting in behavioral changes. This is the first work that studies the mechanism of pheromone treatment in horses and can be applied for further study about the effect of pheromone therapy on horses.

Abstract: Androstenone influences the changing behaviors of animals. Previous studies discovered that an androstenone receptor was expressed in horses and treatment with androstenone induced horses to be more compliant. As changes in the level of neuroendocrine factors result in animal behavioral changes, the objective of the study was to monitor the changes in the concentrations of 5 -HT, $\beta$-endorphin, and cortisol in response to androstenone. Eight thoroughbred horses (five mares and three geldings) were treated with androstenone diluted in jojoba oil $(10 \mu \mathrm{g} / \mathrm{mL})$ and only oil for a control cross-overly. A handler applied the treatments to the horses' nostril and rubbed for $5 \mathrm{~s}$. Blood samples were collected before, 15, 30, and 60 min after each treatment. The concentrations of each neurotransmitter were analyzed by enzyme-linked immunosorbent assay. The concentrations of each neurotransmitter after the treatment were compared to its baseline concentration. The concentration of 5-HT of the androstenone-treated horses remained consistent throughout the experiment, while the concentration of the control group significantly decreased over time. The plasma concentration of $\beta$-endorphin in the androstenone-treated group also remained constant, whereas the concentration increased in the control group. Cortisol levels did not change in either the treated or untreated groups. An androstenone treatment triggers changes in the secretion of 5-HT and $\beta$-endorphin in horses.

Keywords: androstenone; horse; neurotransmitter; pheromone

\section{Introduction}

Hormones and/or neurotransmitters act on the nervous system to regulate physiological responses and behavioral changes [1,2]. Several studies suggest that the synthesis and release of hormones and neurotransmitters are mediated by internal or external stimuli including pheromones [3-5]. Pheromones are volatile and non-volatile chemical molecules that usually trigger behavioral changes in the same species of animal [6]. 5 $\alpha$-androst-16-en3 -one (androstenone) is a pheromone contained in boar saliva [7]. We recently reported an 
expression of the androstenone specific receptor (OR7D4) in the vomeronasal organ and nasal cavity of horses [8], indicating that horses have an ability to sense androstenone. In addition, behavioral testing suggests that androstenone treatment induces docile behavior in horses (data not published).

Serotonin, also known as 5-hyxroxytryptamine (5-HT), is a monoamine neurotransmitter and is synthesized from tryptophan by the enzymes tryptophan, hydroxylase, and aromatic amino acid decarboxylase [9]. 5-HT is one of the factors that regulates and modulates the psychological state of animals [10,11]. 5-HT is also involved in the social behaviors of many animal species such as hamsters [9], rats [12], mice [13], dogs [14], and humans [15]. These studies show that high levels of 5-HT promote social interaction and decrease aggression in animals. Thus, the behavioral changes of horses, which see them become more compliant to handlers, caused by pheromone treatment may have a correlation with the 5-HT secretion. The results of previous studies led us to hypothesize that the concentration of plasma 5-HT could be induced by androstenone treatment.

$\beta$-endorphin is an opioid neuropeptide and peptide hormone secreted by certain neurons within the central nervous system (CNS) and peripheral system. $\beta$-endorphin functions to reduce stress and maintain homeostasis in the body. It generally modulates pain perception both in the central and the peripheral nervous systems. With the general characteristics of $\beta$-endorphin, the plasma $\beta$-endorphin may be induced by a series of blood collection stimuli to reduce stress. $\beta$-endorphin secretion also has a correlation with 5-HT secretion because the activation of the endogenous opioid system releasing $\beta$-endorphin is mediated by the serotonergic system [16,17]. Thus, we hypothesized that

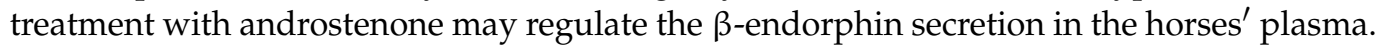

Sport horses, especially racing or endurance horses, often have a high intensity of physical activity that leads to increased stress in the horses [18]. Thus, a treatment that can be used to reduce the stress of equine athletes should be developed because stress can be a limiting factor in the sporting ability of horses [19]. Cortisol is a steroid hormone in the glucocorticoid class and is produced mainly by the zona fasciculate of the adrenal cortex in the adrenal gland $[20,21]$. It is released by the hypothalamic-pituitary-adrenal axis (HPAA). Sustained stress can lead to high levels of circulating cortisol [22]. In the present study, the concentration of plasma cortisol was investigated to monitor the stress level of the horses during the experiment. The plasma cortisol level may increase due to the blood collection procedure. Thus, we hypothesized that treatment with androstenone may down-regulate cortisol secretion during the experimental procedure.

Based on the fact that animal behaviors can be determined by the status of neurotransmitters, we hypothesized that androstenone affects the social interaction between horses and humans via neurotransmitters such as serotonin, $\beta$-endorphin, or cortisol. The objective of this study was to monitor the changes in the concentrations of 5-HT, $\beta$-endorphin, and cortisol in response to androstenone. Thus, the change in the plasma concentrations of 5-HT, $\beta$-endorphin, and cortisol was sequentially monitored before and after treatment with androstenone.

\section{Materials and Methods}

\subsection{Animals}

This study was performed in May. Eight thoroughbred horses were used in this study, consisting of five barren mares and three geldings. The average age of the horses was $12 \pm 1.7$ years. All of the horses were used for horse riding lessons one or two times per day, except on a Monday. The horses were managed in the Sangju International Equestrian Center, Sangju, South Korea. The horses were stabled in private stalls and fed with $2 \%$ body weight (BW) timothy hay and $0.5 \%$ BW commercial concentrate. All of the horses had ad libitum access to water. 


\subsection{Ethical Note}

The research protocol was approved by the Animal Experimentation Ethics Committee of Kyungpook National University (permit number: 2019-0177) and was performed according to the guidelines of the Animal Experimentation Ethics Committee. All of the researchers handled the horses cautiously to minimize the experiment time and stress level of the horses.

\subsection{Pheromone Treatment}

Androstenone (18339-16-7, Sigma-Aldrich, St. Louis, MO, USA) was diluted with jojoba oil (P18C035, Niceday365, Seoul, Korea) at a concentration of $10 \mu \mathrm{g} / \mathrm{mL}$. A handler applied $2 \mathrm{~mL}$ of oil with or without androstenone to the horses' nostril and rubbed for $5 \mathrm{~s}$ wearing latex gloves. For the negative control, jojoba oil without androstenone was used. Treatments with or without androstenone were applied to horses with a cross-over design.

\subsection{Samples}

Approximately $8 \mathrm{~mL}$ of blood was collected from the jugular vein before, 15, 30, and $60 \mathrm{~min}$ after treatment. Blood samples were collected in EDTA tubes (BD Vacutainer, Becton Drive Franklin Lakes, NJ, USA) and maintained in at $4{ }^{\circ} \mathrm{C}$ in an ice box during transportation. The plasma was separated from the whole blood using centrifugation at $1500 \times g$ for $10 \mathrm{~min}$ at $25^{\circ} \mathrm{C}$ and stored in a $-70{ }^{\circ} \mathrm{C}$ refrigerator before analysis.

\subsection{Enzyme Linked Immunosorbent Assay (ELISA) for 5-HT}

The 5-HT was analyzed with plasma using a horse 5-HT ELISA kit (MBS037450, MyBioSource, San Diego, CA, USA) following the manufacturer's protocols. The sensitivity of the kit was $2.0 \mathrm{ng} / \mathrm{mL}$. Analysis was performed with an undiluted sample in duplicate. A microplate reader (Tecan, Männedorf, Switzerland) calculated the concentration of 5-HT in the sample based on an absorbance of a wavelength of $450 \mathrm{~nm}$. The average intra- and inter-assay coefficients of variation were 15 and $15 \%$, respectively.

\subsection{ELISA for $\beta$-Endorphin}

The $\beta$-endorphin was analyzed with plasma using a horse Bep ( $\beta$-endorphin) ELISA kit (IT1465, Immunotag ${ }^{\text {TM }}$, St. Louis, MO, USA) following the manufacturer's protocols. The sensitivity of the kit was less than $9.375 \mathrm{pg} / \mathrm{mL}$. Samples were diluted with a sample dilutant at a ratio of 1:2 and analyzed in duplicate. A microplate reader (Tecan, Switzerland) calculated the concentration of $\beta$-endorphin in the sample based on an absorbance of a wavelength of $450 \mathrm{~nm}$. The average intra and inter assay coefficients of variation were less than 8 and $10 \%$, respectively.

\subsection{ELISA for Cortisol}

The cortisol was analyzed with plasma using a Cortisol ELISA kit (ADI-900-071, Enzo Life Science, New York, NY, USA) following the manufacturer's protocols. The sensitivity of the kit was $56.72 \mathrm{pg} / \mathrm{mL}$. Samples were diluted with a steroid displacement reagent at a ratio of 1:100 and analyzed in duplicate. A microplate reader (Tecan, Switzerland) calculated the concentration of cortisol, $5-\mathrm{HT}$, and $\beta$-endorphin in the samples based on an absorbance of a wavelength of $405 \mathrm{~nm}$. The average intra- and inter-assay coefficients of variation were less than 10.5 and $13.4 \%$, respectively.

\subsection{Statistical Anlalysis}

The interaction effect of each treatment of androstenone on the level of neurotransmitters was assessed using a Mixed GLM model and the SAS program (SAS Institute, Cary, NC, USA). A least square (LS) post-hoc test was applied to test the significant difference in the plasma concentration of neurotransmitters between the treatment and the cortisol group at the same sampling time. Time-dependent hormonal changes were also compared 
using a LS means comparison. The $p$ values of $<0.05$ were considered to be statistically significant $(p<0.05)$.

\section{Results}

\subsection{5-HT Concentration According to the Time of Androstenone Treatment}

Thirty minutes after the control treatment, the plasma 5-HT levels were significantly reduced compared to baseline levels (Table 1). At 15 and $60 \mathrm{~min}$, the 5-HT levels were similar to the initial concentrations in the control group. Interestingly, the 5-HT concentrations of the androstenone-treated animals did not change at 15,30 , or 60 min compared to the baseline.

Table 1. Time dependent plasma 5-HT, $\beta$-endorphin, and cortisol concentrations of androstenone-treated and untreated groups.

\begin{tabular}{|c|c|c|c|c|c|c|c|c|}
\hline & \multicolumn{4}{|c|}{ Control (Oil) } & \multicolumn{4}{|c|}{ Treatment (Androstenone) } \\
\hline & Before & $15 \mathrm{~min}$ & $30 \mathrm{~min}$ & $60 \mathrm{~min}$ & Before & $15 \mathrm{~min}$ & $30 \mathrm{~min}$ & $60 \mathrm{~min}$ \\
\hline $\begin{array}{c}5-\mathrm{HT} \\
(\mathrm{ng} / \mathrm{mL})\end{array}$ & $98.6 \pm 18.3^{a}$ & $92.3 \pm 16.5^{\mathrm{ab}}$ & $90.2 \pm 17.2$ & $93.8 \pm 17.9$ & $94.6 \pm 18.2$ & $94.1 \pm 17.4$ & $91.6 \pm 17.7$ & $89.5 \pm 17.0$ \\
\hline $\begin{array}{c}\beta \text {-endorphin } \\
(\mathrm{pg} / \mathrm{mL})\end{array}$ & $233.6 \pm 30.0$ & $265.7 \pm 33.7^{\mathrm{ab}}$ & $282.2 \pm 35.5^{b}$ & $287.1 \pm 39.5^{b}$ & $300.8 \pm 52.3$ & $302.82 \pm 52.4$ & $282.1 \pm 40.9$ & $303.2 \pm 54.6$ \\
\hline $\begin{array}{l}\text { Cortisol } \\
\text { (ng/mL) }\end{array}$ & $4.9 \pm 1.5$ & $6.0 \pm 0.9$ & $6.5 \pm 1.1$ & $4.9 \pm 0.7$ & $4.8 \pm 0.9$ & $6.2 \pm 1.1$ & $6.2 \pm 1.3$ & $5.2 \pm 0.9$ \\
\hline
\end{tabular}

a, b Different superscripts indicate statistical significance $(p<0.05)$.

\section{2. $\beta$-Endorphin Concentration According to the Time of Androstenone Treatment}

The concentration of $\beta$-endorphin at 15 and $30 \mathrm{~min}$ after oil-only treatment significantly increased compared to the sample collected before the treatment (Table 1). However, the concentration of $\beta$-endorphin at $60 \mathrm{~min}$ after the oil treatment showed no significant change. Unlike the results of the control group, there was no change in the levels of plasma $\beta$-endorphin in the androstenone-treated animals at 15,30, and 60 min after treatment, compared to the baseline concentration.

\subsection{Cortisol Concentration According to the time of Androstenone Treatment}

The cortisol concentrations remained unchanged throughout the duration of testing in the control group and in the androstenone-treated group (Table 1).

\section{Discussion}

Several studies have demonstrated that pheromones elicit changes in the endocrine system $[23,24]$. In the present study, the plasma concentration of 5-HT in the control group significantly decreased $30 \mathrm{~min}$ after oil treatment, while the treatment group maintained similar levels of 5-HT concentration during the experiment. 5-HT is one of the key factors that regulate and modulate the psychological state of animals $[10,11]$, and the role is important in animal behavior involving anxiety $[25,26]$. The minor pain caused by the repeated blood collection may have induced uneasiness in the horses, which may have contributed to the decrease in the plasma 5-HT concentration. 5-HT is involved in systems that are able to modulate the transmission and processing of nociceptive information [27]. In the treatment group, the plasma concentration of 5-HT did not change during the experiment, which suggests that the perception of pain due to the repeated blood collection was attenuated. Thus, it is possible that androstenone treatment facilitated social interactions between the experimenter and the horses, and reduced the discomfort associated with blood collection. This explanation can be supported by our previous data demonstrating that androstenone treatment on horses encouraged the interaction between handlers and horses (data not published). Several studies support the suggestion that social interaction reduces the perception of pain in human subjects [28-30]. Consequentially, the androstenone treatment seemed to increase the pain threshold of the horses through continuing 5-HT secretion. 
$\beta$-endorphin is an opioid neuropeptide that functions to reduce stress and maintain homeostasis in the body, and generally modulates pain perception both in the central and the peripheral nervous systems [31]. In horses, plasma $\beta$-endorphin can be used as an indicator of stress and pain [32]. McCarthy et al. suggested that the application of an upper lip twitch to horses results in a dramatic increase in the plasma $\beta$-endorphin concentration. Similarly, in our study, we found that $\beta$-endorphin levels were elevated at the 15- and 30-minute blood collections in the control group, indicating that repeated blood collection causes enough pain to release $\beta$-endorphins. Interestingly, the concentration of $\beta$ endorphins in the treatment group showed no significant change during the series of blood collections. Endorphins inhibit the pain signaling pathway [33]. Thus, the androstenone had an analgesic effect that increased the pain threshold of the horses. The activation of the endogenous opioid system that released $\beta$-endorphins is mediated by the serotonergic system $[16,17]$. The result of the $\beta$-endorphin concentration in response to the androstenone treatment may be associated with the maintenance of 5-HT levels and the social buffering of pain perception.

Plasma cortisol is produced when the HPAA is activated by stressors, and the concentration of plasma cortisol has been used as a marker for determining a stress response [34]. In the case of mice, single or multiple injections moderately increased the plasma corticosterone concentrations [35]. The authors suggested that handling or injection could be stressors affecting the physiological parameters [35]. We hypothesized that the series of blood collections using a syringe might cause a stress response in the horses, inducing a plasma cortisol increase. In addition, we expected the androstenone treatment to down-regulate cortisol secretion. However, we found that there was no significant change in the concentration of cortisol in both the treatment and control group. In a study of race horses, cortisol levels during venous catheter placement did not differ significantly from the baseline [36]. This means that venipuncture should not involve high stress to horses. The most effective factors for activating the HPAA system that induces increasing glucocorticoids are generally fearfulness, which is derived from unexpected environmental challenges that are threatening mental or bodily stability in horses [37]. Thus, the repeated blood collection during the study was not as critical as to increase the plasma cortisol concentration. Further study is needed to determine whether androstenone treatment has an effect on plasma cortisol in response to moderate or intense stress.

\section{Conclusions}

Androstenone treatment triggers a constant secretion of 5-HT in horses that sees them become more tolerant of discomfort. Thus, androstenone could be used as an effective aid to calm horses.

Author Contributions: Conceptualization, Y.C. and M.Y.; methodology, Y.C. and M.Y.; software, Y.C.; validation, Y.C. and M.Y.; formal analysis, Y.C. and M.Y.; investigation, Y.C. and M.Y.; resources, M.Y.; data curation, Y.C. and M.Y.; writing - original draft preparation, Y.C.; writing-review and editing, M.Y.; visualization, Y.C.; supervision, M.Y.; project administration, Y.C.; funding acquisition, Y.C. and M.Y. All authors have read and agreed to the published version of the manuscript.

Funding: This research was funded by the National Research Foundation of Korea (NRF), grant number 2019R1A2C1003701.

Institutional Review Board Statement: The research protocol was approved by the Animal Experimentation Ethics Committee of Kyungpook National University (permit number: 2019-0177).

Data Availability Statement: The data presented in this study are available within the article.

Acknowledgments: The authors wish to thank Junyoung Kim and Youngwook Jung for their assistance in data collection. Sangju International Equestrian Center provided the subject horses for this study. The authors also thank the Korean Racing Authority for their assistance.

Conflicts of Interest: The authors declare no conflict of interest. 


\section{References}

1. Avraham, Y.; Hants, Y.; Vorobeiv, L.; Staum, M.; Ahmad, W.A.; Mankuta, D.; Galun, E.; Arbel-Alon, S. Brain neurotransmitters in an animal model with postpartum depressive-like behavior. Behav. Brain Res. 2017, 326, 307-321. [CrossRef]

2. Bacqué-Cazenave, J.; Bharatiya, R.; Barrière, G.; Delbecque, J.-P.; Bouguiyoud, N.; Di Giovanni, G.; Cattaert, D.; De Deurwaerdère, P. Serotonin in animal cognition and behavior. Int. J. Mol. Sci. 2020, 21, 1649. [CrossRef] [PubMed]

3. Gliksberg, M.; Levkowitz, G. Smells familiar: Pheromone-induced neurotransmitter switching mediates social discrimination. Neuron 2017, 95, 1229-1231. [CrossRef] [PubMed]

4. Raina, A.K.; Menn, J.J. Endocrine regulation of pheromone production in Lepidoptera. In Pheromone Biochemistry; Elsevier: Amsterdam, The Netherlands, 1987; pp. 159-174.

5. Dulcis, D.; Lippi, G.; Stark, C.J.; Do, L.H.; Berg, D.K.; Spitzer, N.C. Neurotransmitter switching regulated by miRNAs controls changes in social preference. Neuron 2017, 95, 1319-1333.e5. [CrossRef]

6. Yonezawa, T.; Koori, M.; Kikusui, T.; Mori, Y. Appeasing pheromone inhibits cortisol augmentation and agonistic behaviors during social stress in adult miniature pigs. Zool. Sci. 2009, 26, 739-744. [CrossRef]

7. Oskam, I.C.; Lervik, S.; Tajet, H.; Dahl, E.; Ropstad, E.; Andresen, Ø. Differences in testosterone, androstenone, and skatole levels in plasma and fat between pubertal purebred Duroc and Landrace boars in response to human chorionic gonadotrophin stimulation. Theriogenology 2010, 74, 1088-1098. [CrossRef]

8. Choi, Y.; Yoon, M. The expression of androstenone receptor (OR7D4) in vomeronasal organ and olfactory epithelium of horses. Domest. Anim. Endocrinol. 2020, 74, 106535. [CrossRef] [PubMed]

9. Mohammad-Zadeh, L.; Moses, L.; Gwaltney-Brant, S. Serotonin: A review. J. Vet. Pharmacol. Ther. 2008, 31, 187-199. [CrossRef]

10. Jacobs, B.L.; Azmitia, E.C. Structure and function of the brain serotonin system. Physiol. Rev. 1992, 72, 165-229. [CrossRef]

11. Bari, A.; Robbins, T.W. Inhibition and impulsivity: Behavioral and neural basis of response control. Prog. Neurobiol. 2013, 108, 44-79. [CrossRef]

12. Homberg, J.R.; Schiepers, O.J.; Schoffelmeer, A.N.; Cuppen, E.; Vanderschuren, L.J. Acute and constitutive increases in central serotonin levels reduce social play behaviour in peri-adolescent rats. Psychopharmacology 2007, 195, 175. [CrossRef]

13. Holmes, A.; Murphy, D.L.; Crawley, J.N. Reduced aggression in mice lacking the serotonin transporter. Psychopharmacology 2002, 161, 160-167. [CrossRef] [PubMed]

14. León, M.; Rosado, B.; García-Belenguer, S.; Chacón, G.; Villegas, A.; Palacio, J. Assessment of serotonin in serum, plasma, and platelets of aggressive dogs. J. Vet. Behav. 2012, 7, 348-352. [CrossRef]

15. Young, S.N.; Leyton, M. The role of serotonin in human mood and social interaction: Insight from altered tryptophan levels. Pharmacol. Biochem. Behav. 2002, 71, 857-865. [CrossRef]

16. Zangen, A.; Nakash, R.; Roth-Deri, I.; Overstreet, D.; Yadid, G. Impaired release of $\beta$-endorphin in response to serotonin in a rat model of depression. Neuroscience 2002, 110, 389-393. [CrossRef]

17. Sacerdote, P.; Brini, A.; Mantegazza, P.; Panerai, A.E. A role for serotonin and beta-endorphin in the analgesia induced by some tricyclic antidepressant drugs. Pharmacol. Biochem. Behav. 1987, 26, 153-158. [CrossRef]

18. Witkowska-Piłaszewicz, O.; Grzędzicka, J.; Seń, J.; Czopowicz, M.; Żmigrodzka, M.; Winnicka, A.; Cywińska, A.; Carter, C. Stress response after race and endurance training sessions and competitions in Arabian horses. Prev. Vet. Med. 2021, 188, 105265. [CrossRef]

19. Bartolomé, E.; Cockram, M.S. Potential effects of stress on the performance of sport horses. J. Equine Vet. Sci. 2016, 40, 84-93. [CrossRef]

20. Dickerson, S.S.; Kemeny, M.E. Acute stressors and cortisol responses: A theoretical integration and synthesis of laboratory research. Psychol. Bull. 2004, 130, 355. [CrossRef]

21. Taylor, S.E.; Klein, L.C.; Lewis, B.P.; Gruenewald, T.L.; Gurung, R.A.; Updegraff, J.A. Biobehavioral responses to stress in females: Tend-and-befriend, not fight-or-flight. Psychol. Rev. 2000, 107, 411. [CrossRef]

22. Ambrojo, K.S.; Corzano, M.M.; Poggi, J.C.G. Action Mechanisms and Pathophysiological Characteristics of Cortisol in Horses; IntechOpen: London, UK, 2018; p. 185.

23. Fabre-Nys, C.; Kendrick, K.M.; Scaramuzzi, R.J. The "ram effect": New insights into neural modulation of the gonadotropic axis by male odors and socio-sexual interactions. Front. Neurosci. 2015, 9, 111. [CrossRef]

24. Jacob, S.; Spencer, N.A.; Bullivant, S.B.; Sellergren, S.A.; Mennella, J.A.; McClintock, M.K. Effects of breastfeeding chemosignals on the human menstrual cycle. Hum. Reprod. 2004, 19, 422-429. [CrossRef]

25. Payet, J.M.; Wilson, K.E.; Russo, A.M.; Angiolino, A.; Kavanagh-Ryan, W.; Kent, S.; Lowry, C.A.; Hale, M.W. Involvement of dorsal raphe nucleus serotonergic systems in social approach-avoidance behaviour and in the response to fluoxetine treatment in peri-adolescent female BALB/c mice. Behav. Brain Res. 2021, 408, 113268. [CrossRef]

26. Wang, Z.; Whiteside, S.P.H.; Sim, L.; Farah, W.; Morrow, A.S.; Alsawas, M.; Barrionuevo, P.; Tello, M.; Asi, N.; Beuschel, B.; et al. Comparative Effectiveness and Safety of Cognitive Behavioral Therapy and Pharmacotherapy for Childhood Anxiety Disorders: A Systematic Review and Meta-analysis. JAMA Pediatrics 2017, 171, 1049-1056. [CrossRef]

27. Bardin, L. The complex role of serotonin and 5-HT receptors in chronic pain. Behav. Pharmacol. 2011, 22, 390-404. [CrossRef]

28. López-Martínez, A.E.; Esteve-Zarazaga, R.; Ramírez-Maestre, C. Perceived social support and coping responses are independent variables explaining pain adjustment among chronic pain patients. J. Pain 2008, 9, 373-379. [CrossRef] [PubMed] 
29. Brown, J.L.; Sheffield, D.; Leary, M.R.; Robinson, M.E. Social support and experimental pain. Psychosom. Med. 2003, 65, $276-283$. [CrossRef] [PubMed]

30. Guillory, J.E.; Hancock, J.T.; Woodruff, C.; Keilman, J. Text messaging reduces analgesic requirements during surgery. Pain Med. 2015, 16, 667-672. [CrossRef]

31. Li, C.H. b-Endorphin; Elsevier: Amsterdam, The Netherlands, 2012.

32. McCarthy, R.; Jeffcott, L.; Clarke, I. Preliminary studies on the use of plasma $\beta$-endorphin in horses as an indicator of stress and pain. J. Equine Vet. Sci. 1993, 13, 216-219. [CrossRef]

33. Stefano, G.B.; Ptáček, R.; Kuželová, H.; Kream, R.M. Endogenous morphine: Up-to-date review 2011. Folia Biol. $2012,58,49-56$.

34. Zorn, J.V.; Schür, R.R.; Boks, M.P.; Kahn, R.S.; Joëls, M.; Vinkers, C.H. Cortisol stress reactivity across psychiatric disorders: A systematic review and meta-analysis. Psychoneuroendocrinology 2017, 77, 25-36. [CrossRef] [PubMed]

35. Drude, S.; Geissler, A.; Olfe, J.; Starke, A.; Domanska, G.; Schuett, C.; Kiank-Nussbaum, C. Side effects of control treatment can conceal experimental data when studying stress responses to injection and psychological stress in mice. Lab Anim. 2011, 40, 119-128. [CrossRef] [PubMed]

36. Peeters, M.; Sulon, J.; Beckers, J.F.; Ledoux, D.; Vandenheede, M. Comparison between blood serum and salivary cortisol concentrations in horses using an adrenocorticotropic hormone challenge. Equine Vet. J. 2011, 43, 487-493. [CrossRef] [PubMed]

37. Mills, P.C.; Ng, J.C.; Kramer, H.; Auer, D.E. Stress response to chronic inflammation in the horse. Equine Vet. J. 1997, 29, 483-486. [CrossRef] 